\title{
A Pilot Study Quantifying Filipino Nurses’ Perception of Stress
}

\author{
Elizabeth M. Andal \\ California State University, Bakersfield
}

\begin{abstract}
To understand stress in the context of differences in cultural perception, this study begins to explore stress levels in Filipino registered nurses. Stressors, in this study, include factors such as: death and dying, conflict with physicians, inadequate preparations, problems with peers, problems with supervisors, workload, uncertainty concerning treatment, problems with patients and their families, and discrimination. Using the questions derived from the Expanded Nursing Stress Scale (ENSS) by Lenton et al. (2000), thirty Filipino registered nurses were requested to complete a questionnaire voluntarily without providing any identifying information. This study is a preliminary exploration of stress levels in Filipino nurses and no generalizations can be made from these results. Data analysis revealed interesting information as to variability in perception of stress levels regarding certain factors. Discussions elucidate on various stress factors in the context of the Filipino culture. Further study regarding stress levels is greatly needed particularly in the light of the nursing shortage especially during the evening and night shifts. Stress management programs can be enhanced through the use of the ENSS as a diagnostic tool to identify specific factors considered relevant by the nurses concerned.
\end{abstract}

(C) 2006 Californian Journal of Health Promotion. All rights reserved.

Keywords: RN, registered nurses, Filipino, stress

\section{Background}

For over a decade, the nursing profession has been increasingly characterized by occupational stress, job turnover, and job dissatisfaction (Cooper, 1986; Hawley, 1992). Stress can be described as a dynamic and reciprocal relationship between the person and the environment (Lazarus \& Folkman, 1984). It can be viewed as experiential phenomenon where the individual is exposed to a range of external, environmental demands may include a wide range: from minute daily problems of increased workload or responsibilities to catastrophic life events of death of one's life partner or financial or economic pressures. Nurses employed in hospitals come from a variety of cultural backgrounds. A critical factor in stress levels is how a nurse values a particular stressor based on his/her cultural orientation (i.e., value system assigned to certain social factors).

Demographic considerations in the labor force are particularly important especially in the light of the nursing shortage, both here and abroad
(Brewer and Korner 2001; Buchan 2002; Buerhaus, 2002). There are stressors in the workplace that play a significant role in employee turnover and retention. Of critical importance is patient workload. The nursing staff ratio is known to be a factor in quality of care (Buerhaus et al., 2002; Steinbrook, 2002). There is concern about issues of staff quality in a marketplace where high demand has driven salaries up, schools of nursing being set up quickly to deal with the student waiting list here and abroad (Wickett and McCutcheon, 2002). Some note factors in the work environments (Needleman, 2004). These variables play potential roles as stressors in the patient care settings.

The stress factors in the retention of nursing staff were highlighted by several authors (Anderson, 1991; Tyler and Cushway, 1995). The bodies of evidence available emphasize the importance of stress prevention and subsequent burnout leading to staff turnover. We need not mention the dollar implications of increased 
staff turnover in the light of the increasing costs of recruitment, orientation and staff training. However, such stress management programs can only be effective when cultural factors in stress perception are considered. Understanding stress from the perspective of ethno-cultural differences is an immense task. In the south Florida area alone, we find international nursing students from South and Central America, Jamaica, or the Caribbean Islands.

The present nursing workforce include many Filipino nurses, Hispanic nurses from Cuba, African-American nurses, and AngloCaucasians. No doubt, we have such a multiethnic, multi-cultural nursing workforce. Nursing managers attempt to find ways to help staff nurses cope with daily stressors but many are unsure of where to start. There are biases and stereotypes regarding nurses based on their background. Ironically, many management approaches utilized in "stress management" programs are based on "Anglo-Caucasian" value-system.

To understand stress in the context of differences in cultural perception, this study begins to explore stress levels in Filipino registered nurses. Historically, many U.S. hospitals have recruited nurses from the Philippines to alleviate staffing shortages. The Filipino nurses' traditions, cultural background, which may affect their perception of stressors in the workplace, is of interest as these nurses comprise a substantial part of the nursing workforce in many U. S. hospitals and abroad. Stressors, in this study, include factors such as: death and dying, conflict with physicians, inadequate preparations, problems with peers, problems with supervisors, workload, uncertainty concerning treatment, problems with patients and their families, and discrimination.

\section{Methods}

Chapters of the Philippine Nurses' Association in Florida were contacted via correspondence with a brief description of the proposal and an attached sample questionnaire. Interested chapter officers were identified and requested to distribute the ENSS questionnaire during the association meetings. The volunteer nurses completed background information regarding active registered nurse licensure in the State, patient unit and shift assignment. Completion of the questionnaire is expressed, informed consent to participate in the study. Anonymity of respondents was assured through aggregated data with identity not traceable to specific nurses in any manner. Questionnaires were collected by each chapter volunteer and mailed to the investigator for tabulation. There were fifty-one questionnaires received. Selection criteria for inclusion in the study were: licensure as a registered nurse in Florida and at least one-year of patient unit assignment in the capacity as a registered nurse. Questionnaires indicating otherwise were not included in the data analysis. Thus, the total sample size for this pilot study is thirty (30).

\section{Instrument}

The Expanded Nursing Stress Scale (ENSS) was used in this study. See French, Lenton, Walters, and Eyles (2000) for reliability and validity data. The Expanded Nursing Stress Scale questionnaire was used in this study. The scale is designed to measure nurse stress levels categorized as: death and dying, conflict with physicians, inadequate preparation, problems with peers, problems with supervisors, workload, uncertainty concerning treatment, patients and their families, and discrimination). The ENSS (French, et al.) consists of 59 items with response options in a Likert-like format (1= never stressful, 2 = occasionally stressful, $3=$ frequently stressful, 4 = extremely stressful, $5=$ does not apply). The questionnaires were distributed during the Filipino nurses' meetings. Nurses, wishing to participate, completed the questionnaires and submitted these to the chapter volunteers.

\section{Procedure and Analysis}

Upon receipt of the completed questionnaires via mail, responses meeting set criteria of a minimum of one year patient care assignment as a registered nurse were compiled. Ratings for each question were added and averages calculated. Tables show data tabulated and average points calculated for each question by factor. The results are presented with the 
corresponding questions under each stress factor for clarity.

\section{Results and Discussion}

The ENSS (French, et al) identified the nursing stress factors as death and dying, conflict with physicians, inadequate preparation, problems with peers, problems with supervisors, workload, uncertainty concerning treatment, patients and their families, and discrimination. The nurses' perception of stress is a function of one's frame of reference. A total of thirty $(\mathrm{N}=30)$ completed questionnaires were in this pilot study. The ENSS stress factor ratings by the volunteer nurses were based on the interpretation of the work experience. The following tabulation of nursing stress factors show interesting phenomena.

As nurses, we are faced with both life and death situations. Our feelings about our own mortality, and how we are socialized through the years, influence how we face death and dying as we care for patients. The nurses rated the question, "Watching a patient suffer" most stressful (2.8). The other items such as painful procedures, helplessness in cases where patients fail to improve, and the death of a patient were rated "occasionally stressful."

\section{Death and Dying Stressors}

The process of suffering is perceived as most stressful here (2.80) (see Table 1). One might envision a case scenario of inevitable death with the nurse ministering to the needs of both the patient and family. Indeed, one would have to be stoic, unattached or indifferent to not feel emotionally in pain. In the Filipino culture, overt expression of emotion is not encouraged. Perhaps, even repression of an emotional state may be more stressful and certainly warrants further study.

Table 1

Nursing Stress Factor 1. Mean Levels of Death and Dying Stressors

\begin{tabular}{|l|c|}
\hline \multicolumn{1}{|c|}{ Stressor } & Mean Stress Level \\
\hline Performing procedures that patients experience as painful & 2.26 \\
\hline Feeling helpless in the case of a patient who fails to improve & 2.20 \\
\hline Listening or talking to a patient about his/her approaching death & 2.00 \\
\hline The death of a patient & 2.50 \\
\hline The death of a patient with whom you developed a close relationship & 2.00 \\
\hline Physician(s) not being present when a patient dies & 2.10 \\
\hline Watching a patient suffer & 2.80 \\
\hline
\end{tabular}

\section{Conflict With Physician Stressors}

Criticism by a physician (2.75), making a decision concerning a patient when the physician is unavailable (2.74), and conflict with a physician (2.66) were rated highest by the nurses in the sample population (see Table 2). Negative perception of one's work or how the staff nurse interacts with the physician in the work setting is an important variable in stress level rating. It can only be surmised that in a situation where a physician is unavailable, the nurse is forced to make a prudent decision, then a criticism results from such action resulting in a no-win situation. A nurse has to work under such circumstances and maintain professional composure. Such scenarios occurring repeatedly could possibly influence a nurse's decision to leave the source of stress, in this case maybe request transfer to a different unit to avoid the physician in question. Some may chose to leave the hospital altogether. 
Table 2

Nursing Stress Factor 2. Mean Stress Levels of Conflict with Physician Stressors

\begin{tabular}{|l|c|}
\hline \multicolumn{1}{|c|}{ Stressor } & Mean Stress Level \\
\hline Criticism by a physician & 2.75 \\
\hline Conflict with a physician & 2.66 \\
\hline Disagreement concerning the treatment of a patient & 2.13 \\
\hline Making a decision concerning a patient when the physician is unavailable & 2.74 \\
\hline Having to organize doctor's work & 2.40 \\
\hline
\end{tabular}

\section{Inadequate Emotional Preparation Stressors} The nurses rated this factor between never stressful to occasionally stressful for all three questions (see Table 3). If we look at the totality of a patient care delivery system, there is a tremendous importance on the completion of routine procedures in an almost mechanistic fashion. There is focus on compliance with policies and procedures, as well as risk management. Hospital education departments generally address accreditation guidelines first, and staff nurses' preparation is approached from a skill-competence perspective, rather than emotional preparation.

\section{Problems With Peers Stressors}

Lack of opportunity to talk openly with other personnel about problems in the work setting was rated highest at 2.33 (see Table 4). The rising acuity of patients, increasing emphasis on early discharge, give nurses little (if at all) to socialize or discuss problems with each other. This factor, rated low in the stress level scale may indicate the level of importance peer discussion or support may have. Incidentally, it can be pointed out that one Filipino cultural aspect here is that it is impolite to discuss issues openly. Since this is an accepted state, i.e. not talking openly, a Filipino nurse could not rate this as very stressful.

Table 3

Nursing Stress Factor 3. Mean Stress Levels of Inadequate Emotional Preparation Stressors

\begin{tabular}{|l|c|}
\hline \multicolumn{1}{|c|}{ Stressor } & Mean Stress Level \\
\hline Feeling inadequately prepared to help with the emotional needs of a patient's family & 1.96 \\
\hline Being asked a question by a patient for which I do not have a satisfactory answer & 2.03 \\
\hline Feeling inadequately prepared to help with the motional needs of a patient & 1.96 \\
\hline
\end{tabular}

Table 4

Nursing Stress Factor 4. Mean Stress Levels of Problems with Peers Stressors

\begin{tabular}{|l|c|}
\hline \multicolumn{1}{|c|}{ Problems With Peers Stressors } & $\begin{array}{c}\text { Mean Stress } \\
\text { Level }\end{array}$ \\
\hline Lack of opportunity to talk openly with other personnel about problems in the work setting & 2.33 \\
\hline Lack of opportunity to share experiences / feelings with other personnel in the work setting & 1.80 \\
\hline $\begin{array}{l}\text { Lack of an opportunity to express to other personnel on the unit my negative feelings towards } \\
\text { patients }\end{array}$ & 2.03 \\
\hline Difficulty in working with a particular nurse (or nurses) in my immediate work setting & 2.17 \\
\hline Difficulty in working with a particular nurse (or nurses) outside my immediate work setting & 2.00 \\
\hline Difficulty in working with nurses of the opposite sex & 1.50 \\
\hline
\end{tabular}




\section{Problems with Supervision Stressors}

Not surprisingly, the lack of support by nursing administration was perceived as most stressful (2.77) by the sample nurses, so is lack of support from other health care administrators (2.65), lack of support of the immediate supervisor (2.53) and being held accountable for things over which the nurse has no control (2.52) (see
Table 5). Culturally, Filipinos look to supervisors highly and place importance on their roles and title. One's supervisor is considered in a position of authority and therefore able to help in problem solving. When such help is unavailable or perceived as inadequate, the level of stress may be perceived higher.

Table 5

Nursing Stress Factor 5. Mean Stress Levels of Problems with Supervision Stressors

\begin{tabular}{|l|c|}
\hline \multicolumn{1}{|c|}{ Stressors } & Mean Stress Level \\
\hline Conflict with a supervisor & 1.50 \\
\hline Lack of support of my immediate supervisor & 2.53 \\
\hline Criticism by a supervisor & 2.21 \\
\hline Lack of support by nursing administration & 2.77 \\
\hline Being held accountable for things over which I have no control & 2.52 \\
\hline Lack of support from other health care administrators & 2.65 \\
\hline Criticism from nursing administration & 2.33 \\
\hline
\end{tabular}

\section{Workload Stressors}

Rated frequently stressful at 3.0 is "not enough time to complete all nursing tasks" (see Table 6). Following closely are "unpredictable staffing and scheduling (2.81), not enough staff to adequately cover the unit (2.73), and having to make decisions under pressure (2.74). These factors received the highest ratings from the sample nurses. It is known that staffing patterns in hospitals throughout the United States have been dramatically impacted because of the critical nursing shortage and the advancing age of the current nursing workforce. Most Filipino nurses work during the evening and night shifts. This is primarily because visa petitions are justified on the basis of lack of staffing for these shifts and hospital demonstrated "hardship" in filling these positions.

Table 6

Nursing Stress Factor 6. Mean Stress Levels of Workload Stressors

\begin{tabular}{|l|c|}
\hline \multicolumn{1}{|c|}{ Workload Stressors } & Mean Stress Levels \\
\hline Unpredictable staffing and scheduling & 2.81 \\
\hline Not enough time to provide emotional support to the patient & 2.06 \\
\hline Not enough time to complete all of my nursing tasks & 3.00 \\
\hline Too many non-nursing tasks required, such as clerical work & 2.56 \\
\hline Not enough staff to adequately cover the unit & 2.73 \\
\hline Not enough time to respond to the needs of patients' families & 2.40 \\
\hline Demands of patient classification system & 2.06 \\
\hline Having to work through breaks & 2.48 \\
\hline Having to make decisions under pressure & 2.74 \\
\hline
\end{tabular}




\section{Uncertainty Concerning Treatment Stressors}

The sample nurses rated the following stressful (see Table 7): being in charge with inadequate experience (2.86), a physician not being present in a medical emergency (2.77), being exposed to health and safety hazards (2.63), fear of making a mistake in treating a patient (2.58), and inadequate information from a physician regarding the medical condition of a patient (2.52). Filipino nurses recruited by sponsoring hospitals are provided orientation and training.
The sample population here has already passed the R.N. licensing examination and has been in their current positions for at least one year. However, it is possible that some nurses are placed in "charge positions" particularly during the evening and night shifts when the usual charge nurse is on a sick time off or is on vacation. One's feeling of inadequacy can be additionally complicated when an emergency arises and the physician is not present at the time.

Table 7

Nursing Stress Factor 7. Mean Stress Levels of Uncertainty Concerning Treatment Stressors

\begin{tabular}{|l|c|}
\hline \multicolumn{1}{|c|}{ Stressors } & Mean Stress Levels \\
\hline $\begin{array}{l}\text { Inadequate information from a physician regarding the medical condition of a } \\
\text { patient }\end{array}$ & 2.52 \\
\hline A physician ordering what appears to be inappropriate treatment for a patient & 2.40 \\
\hline Fear of making a mistake in treating a patient & 2.58 \\
\hline A physician not being present in a medical emergency & 2.77 \\
\hline Feeling inadequately trained for what I have to do & 2.48 \\
\hline $\begin{array}{l}\text { Not knowing what a patient /patient's family ought to be told about } \\
\text { condition/treatment }\end{array}$ & 2.20 \\
\hline Being in charge with inadequate experience & 2.86 \\
\hline Uncertainty regarding the operation and functioning of specialized equipment & 2.57 \\
\hline Being exposed to health and safety hazards & 2.63 \\
\hline
\end{tabular}

\section{Patient and Family Stressors}

Topping the list are: patients making unreasonable demands (2.77), being blamed for anything that goes wrong (2.69), having to deal with abusive patients (2.68), and being sexually harassed (2.65) (see Table 8). The evening hours are particularly popular for visitors since many come after work periods. Family and friends provide much attention to the patient, possibly finding certain necessary components of care need to be brought to further attention of the nursing staff. Coping with patients, families and visitors place increased pressures on the daily routine of care. Assigning "Blame" to the nurse is counterproductive but is the usual practice in many patient care units. Nursing managers should be particularly astute to look at causes of problems to solve them rather than "assigning blame". This would be ideal but practice reality does not "pause" for corrective action to take place. It is only on retrospective review that these issues can be addressed fully.

\section{Discrimination Stressors}

Rated at 2.37 is the factor "experiencing discrimination because of race or ethnicity"; lowest was "being sexually harassed" (see Table 9). These are notable and reassuring results from this sample of Filipino nurses. It may be conjecture to posit that since Filipino nurses are recruited to help solve a staffing shortage that they are seen as being "helpful" and one might speculate that nurse managers and co-workers would go the extra mile to welcome them. 
Table 8

Nursing Stress Factor 8. Mean Stress Levels of Patient and Family Stressors

\begin{tabular}{|l|c|}
\hline \multicolumn{1}{|c|}{ Patient and Family Stressors } & Mean Stress Levels \\
\hline Patients and families making unreasonable demands & 2.77 \\
\hline Being sexually harassed & 2.65 \\
\hline Being blamed for anything that goes wrong & 2.69 \\
\hline Being the one that has to deal with the patients' families & 2.2 \\
\hline Having to deal with abusive patients & 2.68 \\
\hline Having to deal with abuse from patients' families & 2.21 \\
\hline $\begin{array}{l}\text { Not knowing whether patients' families will report you for } \\
\text { inadequate care }\end{array}$ & 2.51 \\
\hline
\end{tabular}

Table 9

Nursing Stress Factor 9. Mean Stress Levels of Discrimination Stressors

\begin{tabular}{|l|c|}
\hline \multicolumn{1}{|c|}{ Discrimination Stressors } & Mean Stress Levels \\
\hline Being sexually harassed & 1.95 \\
\hline Experiencing discrimination because of race or ethnicity & 2.37 \\
\hline Experiencing discrimination on the basis of sex & 2.05 \\
\hline
\end{tabular}

\section{Summary and Conclusions}

The Filipino nurses rated factors such as lack of opportunity to discuss problems with peers and inadequate emotional preparation as low on the stress scale. Stress factors rated "occasionally or frequently stressful” are:

1. lack of support from nursing administration

2. not enough time to complete all nursing tasks

3. unpredictable staffing and scheduling

4. being in charge with inadequate experience

5. physician not being present in a medical emergency.

6. patients making unreasonable demands
As in any self-report study, caution is necessary in drawing inferences or generalizations. This preliminary study of stress levels perceived by Filipino nurses provided initial pilot data to refocus future studies on variables occurring during the evening and night shifts when most of the Filipino staff nurses are assigned. ENSS, a 59-item stress scale may be useful in a preliminary assessment of nurses prior to institution a "stress management" program at the patient care unit level. This will allow the modification of the stress management program to address specific factors rated as "most stressful.”

\section{References}

Anderson, J. G. (1991). Stress and burnout among nurses: a social network approach. Journal of Social Behavior and Personality, 6(7), 251-272.

Brewer, C., and Korner, C. F. (2001). Is there another nursing shortage? What the data tells us. Nursing Outlook January, 49(1), 20-26.

Buchan, J. (July 2002). International recruitment of nurses: UK case study. Scotland: Queen Margaret University College.

Buerhaus, P., Matlke, S. et al. (2002). Nursing staffing levels and the quality of care in hospitals. New England Journal of Medicine, 346, 1715-1722. 
Cooper, C. L., and Mitchell, S. (1990). Nurses under stress: A reliability and validity study of the NSI. Stress Medicine, 6, 21-24.

French, S. E., Lenton, R., Walters., V. Eyles, J.(2000). An empirical evaluation of an expanded nursing stress scale. Journal of Nursing Measurement, 8(2), 161-78.

Havlovic, S. J., \& Keenan, J. P. (1995). Coping with work stress: The influence of individual differences. In R. Crandall \& P. L. Perrewe (Eds.), Occupational stress: A handbook. Washington: Taylor \& Francis.

Needleman, J. (2004). Working conditions of the nursing workforce: excerpts from a policy roundtable at the Academy Health's 2003 Annual Research Meeting. Health Services Research, 39(3), 445.

Tyler, P. A., and Cushway, D. (1995). Stress in nurses: The effects of coping and social support. Stress Medicine, 11, 243-251.

Wickett, D., and McCutcheon, H. (2002). Issues of quality assessment for nurses in a global market.

Nursing Education Today, 22(1), 44-52.

Author Information

Elizabeth M. Andal, PHD, CNS, APRN-BC, FAAN

Professor

Department of Nursing

California State University, Bakersfield

E-Mail: eandal@csub.edu 